\title{
Research on the Development Trend of the Magazines Publication in China
}

\author{
Xiao-Feng ZHU ${ }^{1,}{ }^{*}$, Xi-Dan YANG ${ }^{2}$, Shu-Yang ZHANG ${ }^{2}$ and Li-Yun PAN ${ }^{1}$ \\ ${ }^{1}$ Department of Basic Science, Beijing Institute of Graphic Communication, Beijing, China \\ ${ }^{2}$ School of Economics and Management, Beijing Institute of Graphic Communication, Beijing, China \\ *Corresponding author
}

Keywords: Publishing industry, Statistical analysis, Regression analysis, Magazines.

\begin{abstract}
Through research for the present challenges and competitions which the development of the publishing industry is facing, the publishing indices which affect development of the publishing industry were determined. Using of the total printed sheets of magazines which is one of important publishing indices of the publishing industry in China, the mathematical models were built to analyze these publishing indices. Based on this model and the analysis of the total printed sheets of the magazines in 1987-2011, the predicted data of their publishing indices in 2012-2016 was calculated. In order to provide useful data for the relevant research departments, and promote development of the publishing industry in China.
\end{abstract}

\section{Introduction}

Nowadays, the publishing industry of our country has become industrialized and large-scaled, and has more regularity in its development. However, as a particular industry, the publishing industry has its own feature in the development. One is that the trend of developing and changing is complicated. Another is that a lot of indicators are needed during the quantitative analysis. And the other is that there are nonlinear relationships between different data. Therefore, how to create a suitable mathematical model, and providing necessary and valuable analyzed data for the publishing industry of our country by the quantitative analysis of it and the searching of the regular information in the developing process, has become a significant issue of the growth of the publishing industry $[1,2]$.

In China, the publishing industry belongs to a special kind of industry which produces and sales cultural products. On one hand, it has a sacred mission of culture accumulation and heritage of civilization. On the other hand, the product of the publishing industry has the general attributes of merchandise, which must be exchanged to implement its value and achieve its political and cultural mission, is for filling the growing spiritual and cultural need of people.

\section{Statistical Analysis for the Magazines Publication}

There are many kinds of publications, which contains traditional publications, like books, newspapers and magazines; electronic publications, like floppy disk, CD-ROM, interactive CD-ROM, and Photo CD, etc. Due to the short developing period of electronic publications, the regularity of its data is weak, so we the authors mainly analyze and research the indicators of traditional publications. In order to research the growth trend of the publishing, we investigate the indices data in the publishing industry of magazines in our country from 1987 to 2011 in Table 1, nearly 25 years in the past, and we draw the data curve is shown in Fig. 1. 
Table 1. Statistics of the total printed sheets for the magazines

[Unit: hundred million sheets]

\begin{tabular}{|c|l|l|l|l|l|l|l|l|l|l|l|l|l|}
\hline Year & 1987 & 1988 & 1989 & 1990 & 1991 & 1992 & 1993 & 1994 & 1995 & 1996 & 1997 & 1998 & 1999 \\
\hline Magazines & 72.7 & 71.2 & 50.7 & 48.1 & 54.4 & 62.7 & 64.2 & 63.9 & 67.0 & 68.1 & 73.3 & 79.9 & 96.8 \\
\hline Year & 2000 & 2001 & 2002 & 2003 & 2004 & 2005 & 2006 & 2007 & 2008 & 2009 & 2010 & 2011 & \\
\hline Magazines & 100.0 & 100.9 & 106.4 & 109.1 & 110.5 & 125.3 & 136.9 & 157.9 & 158.0 & 166.2 & 181.1 & 192.7 & \\
\hline
\end{tabular}

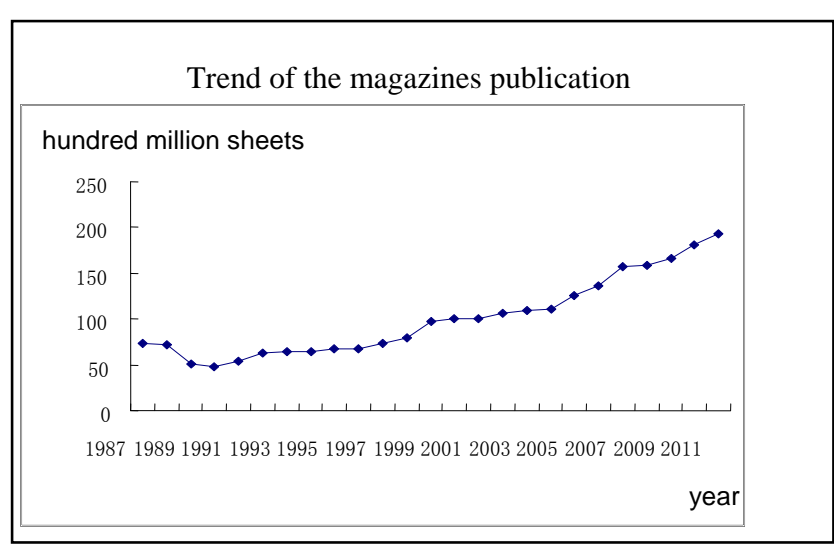

Figure 1. Trend of the magazines publication

\section{Least Squares Method Model}

In the study of statistical methods of scientific experiments, we often need finding out the relationship between variables $x$ and $y$ the dependent variable as a function of $y=f(x)$ from a set of experimental data. Since observation data are often inaccurate, so it does not require the $y=f(x)$ covers all the points, and only require the errors on the given points is the minimum according to a certain standard. Usually we use the Euclidean norm as the standard of error measuring. This is the so called least squares method.

\section{Building and Solving the Mathematical Model}

From 1987 to 2011 ( 25 years), the total printed sheets for magazines is shown in Table 1, and the corresponding data curves in Fig.1. According to this graph you can observe that the development of the national magazines distribution industry is on a gradually rising trend, started slowly, then grew faster. Therefore we used least squares method model to analyze and predict the issuance data of the magazines.

Seen from the graph curves, quadratic polynomials can be used to fit the effects chart of magazines distribution between total sheets and time. Set fitted quadratic polynomial equation is

$$
y=a_{0}+a_{1} t+a_{2} t^{2},
$$

and $t$ is for time (year), $y$ is for the total printed sheets (hundred million) annually.

$$
R=\left(\begin{array}{ccc}
1 & t_{1} & t_{1}^{2} \\
1 & t_{2} & t_{2}^{2} \\
\cdots & \cdots & \cdots \\
1 & t_{n} & t_{n}^{2}
\end{array}\right), A=\left(a_{0}, a_{1}, a_{2}\right)^{T}, Y=\left(y_{1}, y_{2}, \cdots, y_{n}\right)^{T}
$$


$t_{i}(i=1,2, \cdots, 25)$ and $a_{i}(i=0,1,2)$ indicate time and the fitting curve coefficient respectively, $y_{i}$ is the total printed sheets of magazines in $t_{i}(i=1,2, \cdots, 25)$.

From the equation $R^{T} R A=R^{T} Y$, we can get the coefficient $A=\left(a_{0}, a_{1}, a_{2}\right)^{T}$ in the least squares method.

By using the software Mathematica 5.0, we can directly input the data in Table 1, and obtain the curve equation between the total printed sheets and time $t$

$$
y=64.55-2.2756 t+0.2975 t^{2} .
$$

According to this, we got the fitting curve graph is shown in Fig.2.

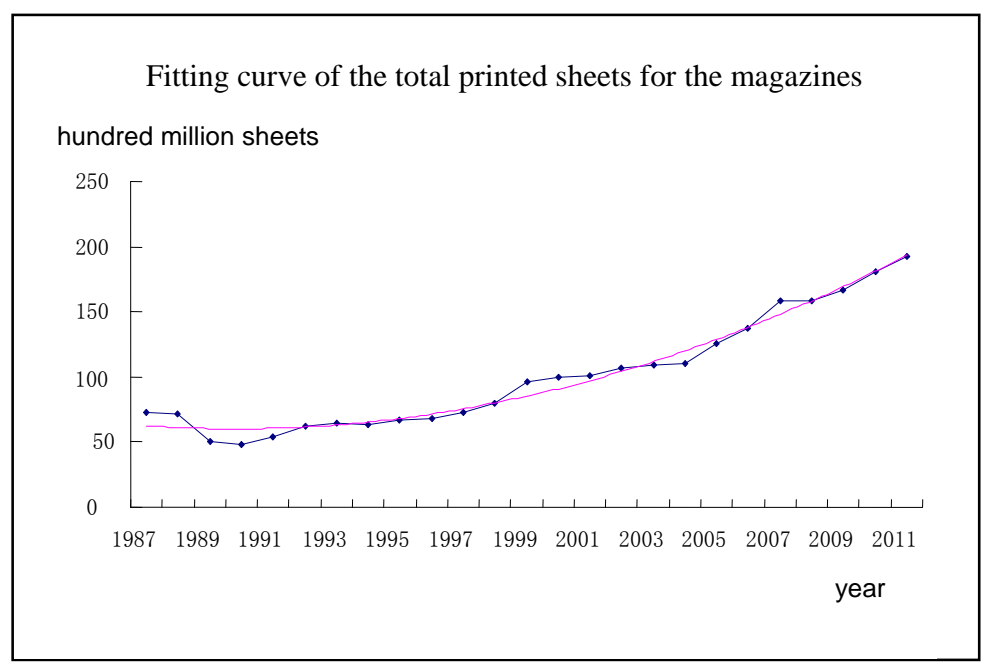

Figure 2. Fitting curve of the total printed sheets for the magazines

\section{Prediction for the Magazines Publication}

According to the comparison of the actual data and the fitted curve data, we tested the fitting equation, it fits the trend. Seen from the fitting function, with the growth over time, the total printed sheets of the magazines increased year by year and it's in linear relationship with time. On one hand, as the level of economic developing, there are a wide range of effects of magazines to a broad range of readers. And they have become a kind of necessary cultural consumer goods in our daily life, passing information with depth from all sides, to the people, which mobile phones and networks are unable to provide, adding fun to people's daily lives. Meanwhile, though there is progressive development of the electronic publications in recent years, but the magazines plays an irreplaceable role in some area. Especially in recent years, the magazines market of China has made great progress in reforms and changes, and also provided favourable conditions for development of magazines publishing. It is reasoned that the total printed sheets of magazines from 2012 to 2016 (the late 12th five-year and early 13th five-year), it is shown in Table 2.

Table 2. The predicted data of magazines publication from 2012 to 2016

[Unit: hundred million sheets]

\begin{tabular}{|c|c|c|c|c|c|}
\hline Year & 2012 & 2013 & 2014 & 2015 & 2016 \\
\hline Total printed sheets of the magazines & 206.49 & 219.99 & 234.07 & 248.76 & 264.03 \\
\hline
\end{tabular}

Among them, the actual data of the magazines in 2012 is 196.01 hundred million sheets, and have little difference with the predicted one, which is only $-5.35 \%$. The model is accurate enough. 


\section{Conclusions}

Two fast-rising GDP growth phase in China is the earlier 80s and the middle 90s of the 20th century, the top speed was in 1984 and 1992.The speed of the growth of the total printed sheets in China reached a top for the first time in 1985, but the continuous growth of the publishing indices of books and magazines stayed in the same direction as the growth of the GDP after the 90s of the 20th century. This indicates that the development of publications made a certain contribution to China's GDP growth.

For nearly 30 years, China's publishing industry have gradually achieved the transformation from "bringing in" to "going out", and the international competitiveness increases. But with the advent of the information age, China's publishing industry also faces a lot of competition and challenges. From the perspective of the statistical analysis, we analyzed the data of the publishing indices for books and magazines publication in1987-2011, and forecasted the data of these publication in the late Twelve-Five and early Thirteen-Five for the next five years. We hope to help the future development of the publishing industry.

\section{Acknowledgement}

The research was supported by the Project for Building Excellent Teaching Team of Beijing Institute of Graphic Communication, Education and Teaching Reform Projects for High School of Beijing (2013-lh08), Key Teaching Reform Projects of Beijing Institute of Graphic Communication, the Plan Projects for College Students' Scientific Research and Entrepreneurial Action of Beijing, Institute Level Key Projects Funded by Beijing Institute of Graphic Communication (Ea201606).

\section{References}

[1] Zhensheng Hao, The report of development for Chinese publishing industry in 2009-2010, China Books Press, 2010.

[2] Guanyi Wang and Yuhong Hua, Study on the performance evaluation of Chinese publishing industry, China Financial and Economic Press, 2010.

[3] The writing group of mathematical model, Mathematical model, South China University of Technology Press, 2001.

[4] Xizu Yan, Zhongmin Song and Chunjia Bi, Mathematical modeling and experiment, Science Press, 2009.

[5] Yaoting Zhang, Misunderstanding on Regression Analysis in Application. Statistical Education, 3,12-14, 1998.

[6] Wuyi Zeng and Hongye Xiao, Statistics Introduction, Science Press, 2012.

[7] Information on http://www.cnki.net.

[8] Information on http://www.stats.gov.cn.

[9] Information on http://www.doc88.com/p-892244711319.html.

[10] Information on http://blog.sina.com.cn/s/blog_1757f60af0100zwfb.html.z 